\title{
DESIGN AND IMPLEMENTATION OF AN AUTO-TEMP CONTROL SYSTEM FOR DISTRIBUTION TRANSFORMER
}

\section{${ }^{* 1}$ Orjiewulu, J.C., ${ }^{2}$ Chukwuemeka, D. C., ${ }^{3}$ Jesusblessing, C.E. and ${ }^{4}$ Ibrahim, A.}

\author{
${ }^{* 1,2,4}$ Department of Electrical Electronics Engineering, University of Benin, Benin City, Edo State, Nigeria. \\ ${ }^{2}$ Phone: $08094988633{ }^{2}$ Email: johnboscoloaded@yahoo.com \\ ${ }^{2}$ Phone: 08147542529 2Email: desmondchukwuemeka14@gmail.com \\ ${ }^{3}$ Department of Physics, University of Benin, Benin City, Edo State, Nigeria. \\ ${ }^{3}$ Phone: 08105287256 ${ }^{3}$ Email: jesusblessingemanuella@yahoo.com \\ ${ }^{4}$ Phone: $08138067300{ }^{4}$ Email: ibrahimmalik85@gmail.com
}

\begin{abstract}
Unreliability and interruptions facing power supply are evidence of the excessive heat generated in power systems, as a result of the inefficiency of oil cooling medium employed in distribution transformers. The design and implementation of a prototype automatic temperature control system is to be employed as a method towards solving the above stated problem of excessive temperature rise in distribution transformers. The prototype design consists of a PIC microcontroller programmed in C language, an LM35 temperature sensor, an electric fan and other diverse electronic component. It operates a mechanism that detects temperature rise in the transformer and automatically turns on the cooling fan at extreme temperature conditions. A 16x2 LCD is employed as the medium for temperature display unit of the transformer. The resulting prototype functions in a way that it has the ability to detect every $1^{\circ} \mathrm{C}$ rise and reduction in the temperature of the transformer. Thus, at extreme temperature conditions, the automatic temperature control system diminishes the excessive heat generated in the transformer to the appropriate working temperature condition.
\end{abstract}

Keywords: cooling, distribution transformers, heat, prototype, PIC microcontroller, temperature control system

LICENSE: This work by Open Journals Nigeria is licensed and published under the Creative Commons Attribution License 4.0 International License, which permits unrestricted use, distribution, and reproduction in any medium, provided this article is duly cited.

COPYRIGHT: The Author(s) completely retain the copyright of this published article.

OPEN ACCESS: The Author(s) approves that this article remains permanently online in the open access (OA) mode.

QA: This Article is published in line with "COPE (Committee on Publication Ethics) and PIE (Publication Integrity \& Ethics)". 


\section{INTRODUCTION}

A transformer can be referred to as a power transmission device system that basically converts one voltage level into another voltage level without altering the frequency of the system. During this conversion process, losses occur in the core and windings of the said system. These losses are generally termed heat losses. As a result of these losses in the transformer. the output power of the transformer drops and returns a bit less than its input power. The increase in the rating and capacity of a transformer directly results to an increase in its generated heat. There are different mediums of cooling system conversant with this power system device, they basically include: air, water, oil mediums of cooling systems. The oil and water-cooling mediums of cooling systems in the past years has been done manually. Due to its manual operation characteristic, it is faced with the disadvantage and challenge of not recognizing over heating (Bharathidasan, et al., 2019).

Transformer design most takes into consideration the thermal behavioral aspect. Therefore, precise and proper temperature calculations to a reasonable extent guarantees good quality, performance and long-life expectancy of transformers. The temperature gradient between conductor and oil consists of a gradient inside the solid winding insulation and a gradient inside the boundary layer at the winding surface must be optimal. The gradient inside the solid insulation depends on the thickness of the enamel, paper insulation and oil pockets between conductor and paper wrapping. The heat transfer at the winding surface of a transformer is determined by the cooling conditions approach. The two basic approaches mostly in use are: The Natural Convective Cooling (ON) and The Forced Convective Cooling (OD).

During the operation of the transformers, heat losses occur and the windings temperature get heated up. Heat losses in the transformer include the losses in iron core, due to the magnetic induction and the copper losses that occur as a result of the flow of electrical current through the windings of the transformer. It is paramount to set up a medium of external cooling system to reduce the heating up of the transformer winding temperature. While the standard average temperatures for the standard-class dry transformers are $80^{\circ} \mathrm{C}, 115^{\circ} \mathrm{C}$ and $150^{\circ} \mathrm{C}$, the temperatures of the hottest point reach $150{ }^{\circ} \mathrm{C}, 185^{\circ} \mathrm{C}$ and $220^{\circ} \mathrm{C}$ respectively. The expected life of transformers at various operating temperatures is not exactly known. (Buyukbicakci et al., 2014).

\section{LITERATURE REVIEW}

Amuthan et al., (2017) designed a quadrant cooling type transformer, in this medium, the transformer is cooled by the exterior fan using solar energy. The fans are located in different quadrants with an angle difference of 45 degrees in each quadrant. This method is synonymous to the ONAF method in which air is blown on the cooling fin of the transformer from four angles thereby generating swift cooling. The fans are directly connected to solar panels in this case therefore constant cooling occurs whenever UV rays comes up.

Tekade and Rakhonde (2014) created a microcontroller-based cooling system for transformers. Transformer cooling control was achieved by using an ATmega8L microcontroller handled the automation cooling mechanism of the transformer. The microcontroller senses excessive rise in the winding temperature and the oil temperature via a temperature indicator and oil temperature indicator and then automatically puts on the fan or trip the transformer 
conditioned on the temperature level of the transformer to curtail overheating and decline in the life span of the transformer life.

Modi (2012) also did a project on the control panel of the transformer employing the services of a microcontroller and power electronics device. In his work, the heat generated in the transformer is transposed directly to the heat sinks and there, cooling mediums (i.e. fans) made available outside the transformer works the transformer walls. The fans outside the transformer are given a parallel form of connection arrangement.

\section{METHODOLOGY}

This section of the article explains the method (i.e. the design consideration and construction) employed in solving the initial stated problems. For the construction of the prototype, the electrical components listed below were employed in the design following due consideration and calculation process. Components are as follows;

- Temperature sensor

- Microcontroller

- LCD display

- Diodes

- Capacitors

- Resistors

- Relay

- Voltage regulator

- Push button

- Buzzer

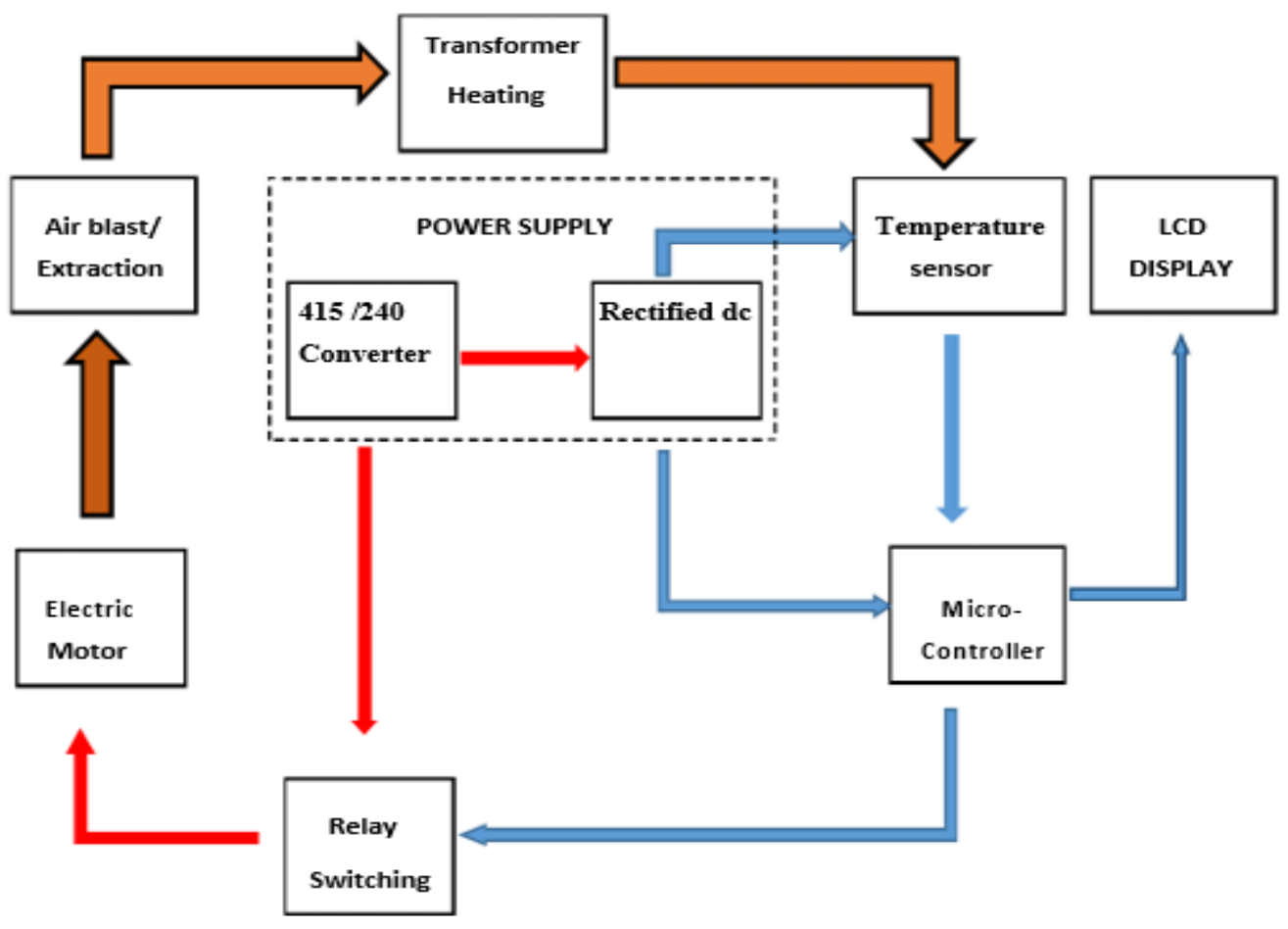

Figure 1: Block diagram for the design consideration 


\section{DESIGN CONSIDERATIONS AND CALCULATION REQUIREMENTS}

The different stages involved in the design of the automatic temperature control system of a distribution transformer are as follows:

1. Power supply.

2. Microcontroller circuit

3. Temperature sensor

4. LCD display unit

5. Buzzer

6. Control buttons

7. Fan

\section{TRANSFORMER}

The transformer is a single-phase step down $220 \mathrm{~V} / 12 \mathrm{~V}$ with a maximum secondary current rating of $0.75 \mathrm{~A}$. Making some design assumptions, let:

$\mathrm{IS}_{\max }=$ Maximum Secondary Current $=0.75 \mathrm{~A}$

$\mathrm{VP}_{\max }=$ Primary Voltage $=220 \mathrm{~V}$

$\mathrm{VS}_{\max }=$ Secondary Voltage $=12 \mathrm{~V}$

PT $=$ Transformer Max. Output Power

$\mathrm{PT}=\mathrm{VS}_{\max } \times \mathrm{IS}_{\max }$

$\mathrm{PT}=12 \mathrm{~V} \times 0.75 \mathrm{~A}=9 \mathrm{VA}$

DIODE BRIDGE

Diodes generally offers a forward voltage drop of 0.7 Volts to every voltage supplied into them and offers a voltage drop of $1.4 \mathrm{~V}$ against every half cycle of the alternating voltage supplied into the bridge. Mathematically, this is expressed below using the following equations.

$\mathrm{VS}_{\max }=$ Input voltage to diode bridge

$\mathrm{V}_{\text {DIODE }}=$ Diode forward Drop $=0.7 \mathrm{~V}$

$\mathrm{V}_{\text {OUT }}=\mathrm{VS}_{\max }-2\left(\mathrm{~V}_{\text {Diode }}\right)$

$\mathrm{V}_{\text {OUT }}=12 \mathrm{~V}-(2 \times 0.7)$

$\mathrm{V}_{\text {OUT }}=10.6 \mathrm{~V}$

The equivalent output DC Voltage from the diode bridge:

$\mathrm{V}_{\mathrm{DC}}=\mathrm{V}_{\text {OUT }} \mathrm{x} 0.7071$

$\mathrm{V}_{\mathrm{DC}}=10.61 \times 0.7071$

$\mathrm{V}_{\mathrm{DC}}=7.501 \mathrm{~V}$

The output power $\left(\mathrm{P}_{\text {out }}\right)$ in watts of the rectifier:

$\mathrm{P}_{\mathrm{out}}=\mathrm{V}_{\mathrm{dc}} \times \mathrm{IS}_{\max }$

$\mathrm{P}_{\text {out }}=7.501 \times 0.75$

$\mathrm{P}_{\text {out }}=5.63 \mathrm{watts}$ 


\section{FILTER CAPACITOR}

A capacitor is placed on the output of the diode bridge to smoothen out ripples from the pulsating DC voltage produced from the diode bridge. The ripple factor is a ratio of the ripple voltage $\left(\mathrm{V}_{\mathrm{RPP}}\right)$ to the $\mathrm{DC}$ voltage on the output of the rectifier.

$\mathrm{V}_{\mathrm{RPP}}=$ Vout $-\mathrm{Vdc}$

$\mathrm{V}_{\mathrm{RPP}}=10.61-7.50$

$\mathrm{V}_{\mathrm{RPP}}=3.11 \mathrm{~V}$

Ripple Factor, $(\gamma)=\mathrm{V}_{\mathrm{RPP}} / \mathrm{V}_{\mathrm{DC}}$

$\gamma=3.11 / 7.501=0.415$

The capacitance of a capacitor suitable to smoothen out an AC voltage with such ripple voltage can be calculated using the expression below

$\mathrm{C}=0.7 * \mathrm{I} / \mathrm{V}_{\mathrm{RPP}} * \mathrm{~F}$

Where,

$\mathrm{I}=$ max output current $=0.75 \mathrm{~A}$

$\mathrm{F}=$ Pulsating DC Frequency $=2 \times \mathrm{AC}$ voltage frequency

$\mathrm{F}=2 \times \mathrm{f}, \mathrm{f}=50 \mathrm{~Hz} ; \mathrm{F}=2 \times 50 \mathrm{~Hz} ; \mathrm{F}=100 \mathrm{~Hz}$

Calculating Peak to peak ripple voltage,

$\mathrm{V}_{\mathrm{RPP}}=$ Peak to peak ripple voltage

$\mathrm{V}_{\mathrm{RPP}}=2 \times \mathrm{Vrpp}$

$\mathrm{V}_{\mathrm{RPP}}=2 \times 3.11 \mathrm{~V}$

$\mathrm{V}_{\mathrm{RPP}}=6.22 \mathrm{~V}$

C = Capacitance of a capacitor,

$\mathrm{C}=(0.7 * 0.75 \mathrm{~A}) /(6.22 * 100 \mathrm{~Hz})$

$\mathrm{C}=0.0008441 \mathrm{~F}$

$\mathrm{C}=844.1 \mu \mathrm{F}$

An $844.1 \mu \mathrm{F}$ capacitor is not feasible, and as such a $1000 \mu \mathrm{F}$ electrolytic capacitor will be employed. The effect of a $1000 \mu \mathrm{F}$ capacitor on the ripple voltage at the output of the rectifier circuit can be calculated using the expression as follows:

Change in $\mathrm{V}_{\mathrm{RPP}}=0.7 * \mathrm{I} / \mathrm{C} * \mathrm{~F}$

Change in $\mathrm{V}_{\mathrm{RPP}}=0.7 * 0.75 / 1000 \mu \mathrm{F} * 100 \mathrm{~Hz}$

$$
=5.25 \mathrm{~V}
$$

$\mathrm{V}_{\mathrm{RPP}}=5.25 \mathrm{~V} / 2$

$\mathrm{V}_{\mathrm{RPP}}=2.625 \mathrm{~V}$

\section{VOLTAGE REGULATOR}

The LM7805 IC voltage regulator can supply a regulated power at 5V and a maximum current of 1A. The LM78XX voltage regulator series can effectively operate when the voltage supplied to its input is at least $2 \mathrm{~V}$ greater than its output voltage. LM7805 whose output is $5 \mathrm{~V}$, the minimum input voltage can is calculated as follows;

$\mathrm{V}_{\min }=\mathrm{V}_{\text {out }}+\mathrm{V}_{\text {ref }}$

Where,

$\mathrm{V}_{\min }=$ minimum input voltage. 
$\mathrm{V}_{\text {out }}=$ required output voltage $=5 \mathrm{~V}$

$\mathrm{V}_{\text {ref }}=$ reference voltage $=2 \mathrm{~V}$

$\mathrm{V}_{\min }=5+2=7 \mathrm{~V}$

$\mathrm{V}_{\mathrm{DC}}=7.501 \mathrm{~V}$ and as such is greater than $7 \mathrm{~V}$, thus the LM7805 can be employed as the voltage regulator. The LM7805 tolerance of $\pm 0.2 \mathrm{~V}$ at its output, hence at full load (i.e. $1 \mathrm{~mA}$ ) its output voltage drops to $4.8 \mathrm{~V}$ as such its percentage voltage regulation is calculated as:

Voltage Regulation $=\left(\mathrm{V}_{\mathrm{NL}}-\mathrm{V}_{\mathrm{FL}}\right) / \mathrm{V}_{\mathrm{F}}$

$\mathrm{V}_{\mathrm{FL}}=$ Full Load voltage

$\mathrm{V}_{\mathrm{NL}}=$ No Load voltage

$\mathrm{V}_{\mathrm{NL}}=5 \mathrm{~V} ; \mathrm{V}_{\mathrm{FL}}=5 \mathrm{~V}-0.2 \mathrm{~V}=4.8 \mathrm{~V}$

$\mathrm{VR}=(5 \mathrm{~V}-4.8 \mathrm{~V} / 4.8) * 100=4.17 \%$

\section{MICROCONTROLLER}

The microcontroller section consists of the power, reset button and the oscillator circuit.

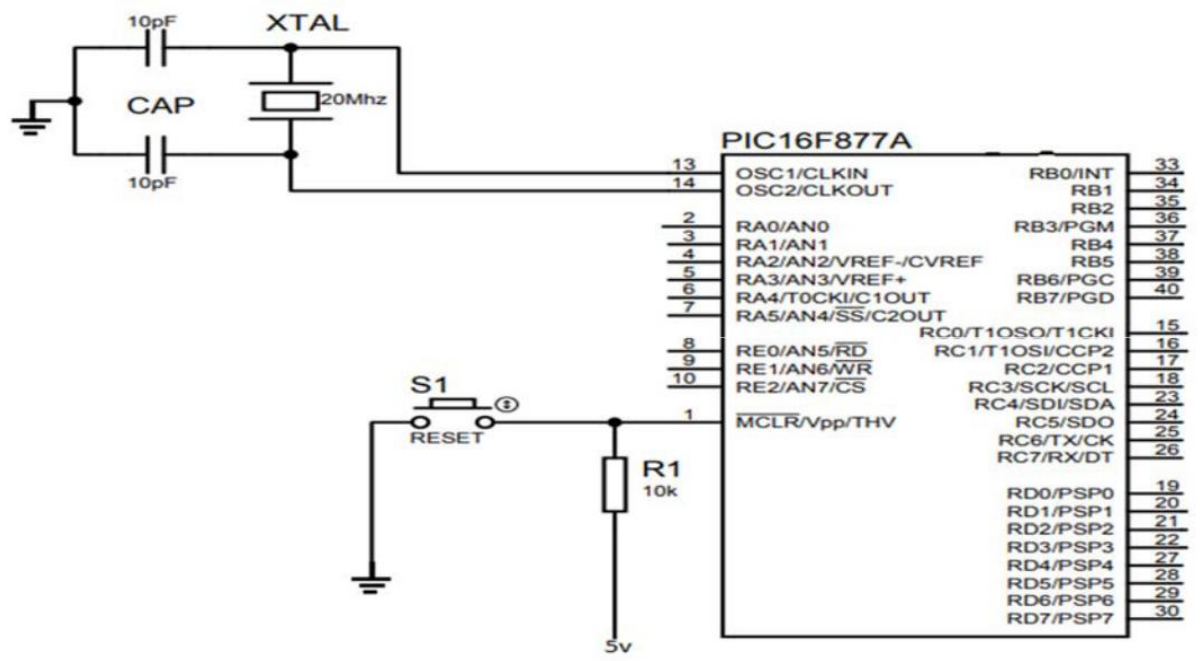

Figure 2: Microcontroller Unit

\section{MICROCONTROLLER POWER SUPPLY}

The microcontroller is supplied with a stable $5 \mathrm{~V}$ at its $\mathrm{V}_{\mathrm{dd}}$ pin 13 and 32 while it is grounded at its $\mathrm{V}_{\text {ss }}$ pin at 12 and 31 respectively.

\section{OSCILLATOR}

The fastest and the maximum working operation of the microcontroller is achieved when it is driven by a $20 \mathrm{MHz}$ oscillator as seen from the microcontroller's datasheet. Microcontroller instruction execution speed is the rate in terms of time in which the microcontroller will execute the commands stored in its program memory.

Microcontroller's instruction execution speed $=(1 /$ Frequency $) * 4$ cycles. At a frequency of $20 \mathrm{MHz}$, the execution speed of the microcontroller can be calculated as;

$(1 / 20000000) * 4$ cycles $=20 \mu \mathrm{S}$ 


\begin{tabular}{|c|c|c|c|c|c|c|}
\hline $\begin{array}{c}\text { Frequency } \\
(\mathrm{MHz})\end{array}$ & $\begin{array}{l}\text { Frequency Tolerance } \\
\text { (ppm max) } \\
\text { [at } 25^{\circ} \mathrm{C} \pm 3^{\circ} \mathrm{C} \text { ] }\end{array}$ & $\begin{array}{l}\text { Frequency Shift } \\
\text { by Temperature (ppm max) } \\
\text { (Standard Condition: }+25^{\circ} \mathrm{C} \text { ) }\end{array}$ & $\begin{array}{c}\text { Frequency } \\
\text { Aging } \\
\text { (ppm max/Year) }\end{array}$ & $\begin{array}{c}\mathrm{ESR}^{*} \\
(\Omega \max .)\end{array}$ & $\begin{array}{l}\text { Load } \\
\text { Capacitance } \\
\text { (pF) } \\
\end{array}$ & $\begin{array}{c}\text { Drive } \\
\text { Level } \\
\text { ( } \mu \text { W max.) } \\
\end{array}$ \\
\hline 20.0000 & \pm 100 & $\pm 100\left(-30\right.$ to $\left.+85^{\circ} \mathrm{C}\right)$ & \pm 5 & 80 & 8 & 300 \\
\hline
\end{tabular}

Figure 3: Datasheet of $20 \mathrm{mhz}$ crystal oscillator

\section{OSCILLATOR LOADING CAPACITOR JUSTIFICATION}

The $20 \mathrm{MHz}$ crystal oscillator uses two supporting capacitors; $\mathrm{C}_{1}$ and $\mathrm{C}_{2}$, these capacitors help ensure that each pulse produced by the crystal oscillator is perfectly timed. The parasitic capacitance $\left(\mathrm{C}_{\text {parasitic }}\right): \mathrm{C}_{\text {parasitic }}=\mathrm{C}_{\text {input }}+\mathrm{C}_{\text {stray }}$

We can therefore calculate value of the capacitors the across the $20 \mathrm{MHz}$ crystal by applying the formula;

$\mathrm{C}_{\mathrm{L}}=1 /\left(1 / \mathrm{C}_{2}+1 / \mathrm{C}_{3}\right)+\mathrm{C}_{\text {Paracitic }}$

Where $\mathrm{C}_{2}=\mathrm{C}_{3}=\mathrm{C}$

$\mathrm{C}_{\mathrm{L}}=1 /(1 / \mathrm{C}+1 / \mathrm{C})+\mathrm{C}_{\text {Paracitic }}$

$\mathrm{C}_{\text {Paracitic }}=0, \mathrm{CL}=$ Loading capacitor $=8 \mathrm{Pf}$

$\mathrm{C}_{\mathrm{L}}=1 /(1 / \mathrm{C}+1 / \mathrm{C})+0$

$\mathrm{C}=2 \times \mathrm{CL} ; \mathrm{C}=2 \times 8 \mathrm{pF}=16 \mathrm{pF}$

A $16 \mathrm{pF}$ capacitor is feasible and as a result a $10 \mathrm{pF}$ ceramic capacitor is employed for the design. This $\mathrm{A} / \mathrm{D}$ Converter module can also operate in sleep mode in which clock is derived from its internal RC oscillator. Following points may help you to understand the concept of reference voltages.

\section{ADC MODULE OF THE PIC MICROCONTROLLER}

Analog to Digital Converter (ADC) is a device that converts an analog quantity (continuous voltage) to discrete digital values. Most of the PIC Microcontrollers have built in ADC Module. In this project, PIC16F877A is used.

When the ADC input is $-\mathrm{V}_{\text {ref }}$, result will be 0000000000

When the ADC input is $+\mathrm{V}_{\text {ref }}$, result will be 111111111

Resolution of $\mathrm{ADC}=\left(+\mathrm{V}_{\text {ref }}--\mathrm{V}_{\text {ref }}\right) /(2-1)$, which is the minimum voltage required to change the ADC result by one bit.

Here ADC Resolution $=(5-0) /(1024-1)=5 / 1023=0.004887 \mathrm{~V}$

So, if the input is $5 \mathrm{~V}$, ADC Value is $5 / 0.004887=1023=11111111$ (binary)

If the input is $0.004887 \mathrm{~V}$, ADC Value is $0.004887 / 0.004887=1=00000001$ (binary)

\section{TEMPERATURE SENSOR}

The LM35 temperature sensor has three terminals pins by which it is connected. Pin 1 is the input pin, pin 2 is the output pin and pin three is the ground pin. Input pin (pin-1) is connected to $5 \mathrm{~V}$ supply, the output pin (pin 2) is connected to an analog input pin (RA0) of the microcontroller and pin 3 of the LM35sensor is grounded. 


\section{LCD UNIT}

The LCD is powered by the system $5 \mathrm{~V}$

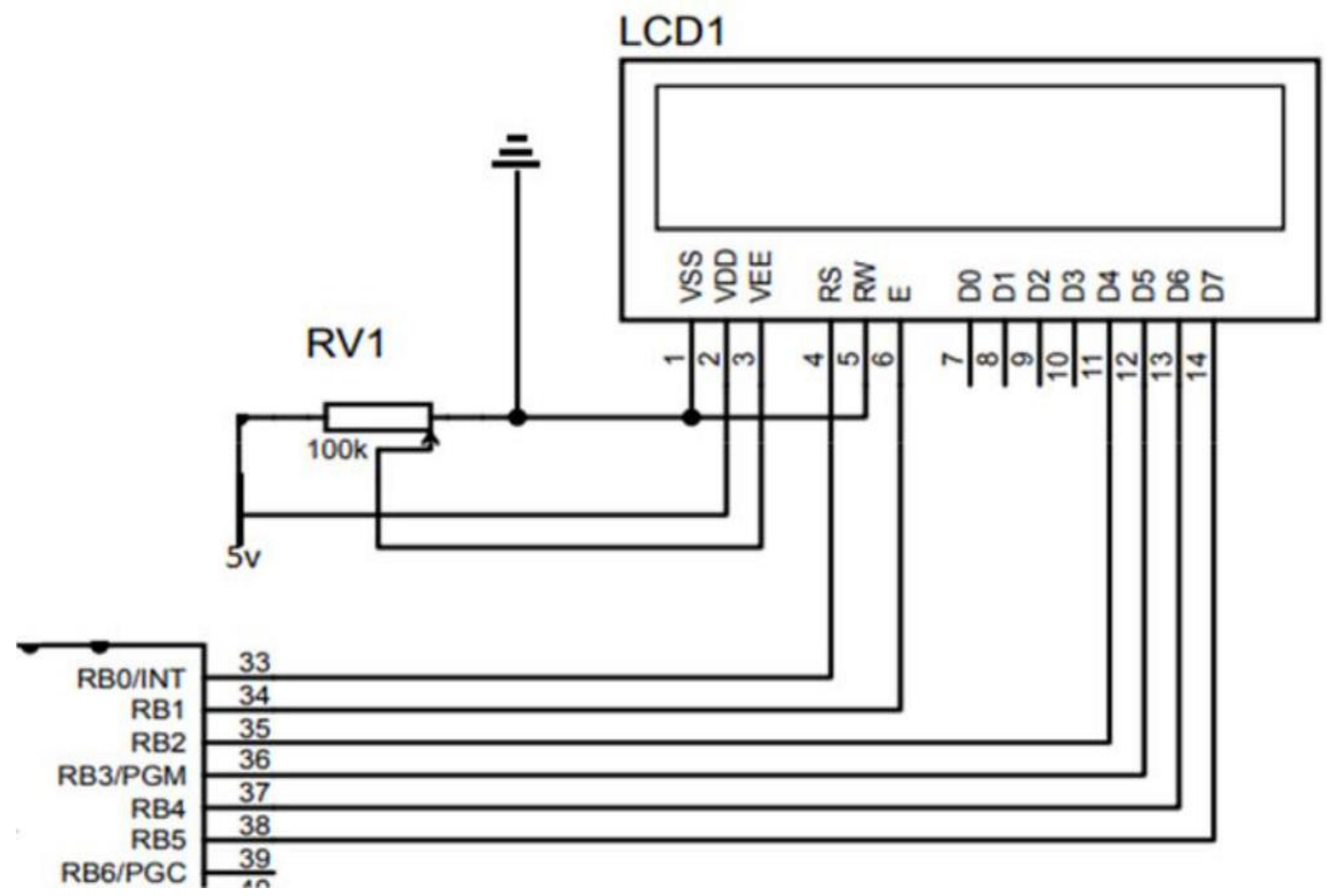

Figure 4: LCD Connection

The connection of the LCD screen is as follows;

RESET (RS) pin is connected to pin 33 of the microcontroller.

ENABLE (E) is connected to pin 34 of the microcontroller.

Data pin4 (D4) was connected to pin 35 of the microcontroller.

Data pin5 (D5) was connected to pin 36 of the microcontroller.

Data pin6 (D6) was connected to pin 37 of the microcontroller.

Data pin6 (D7) was connected to pin 38 of the microcontroller. 


\section{BUZZER}

The buzzer switch was connected to pin 16 of the microcontroller.

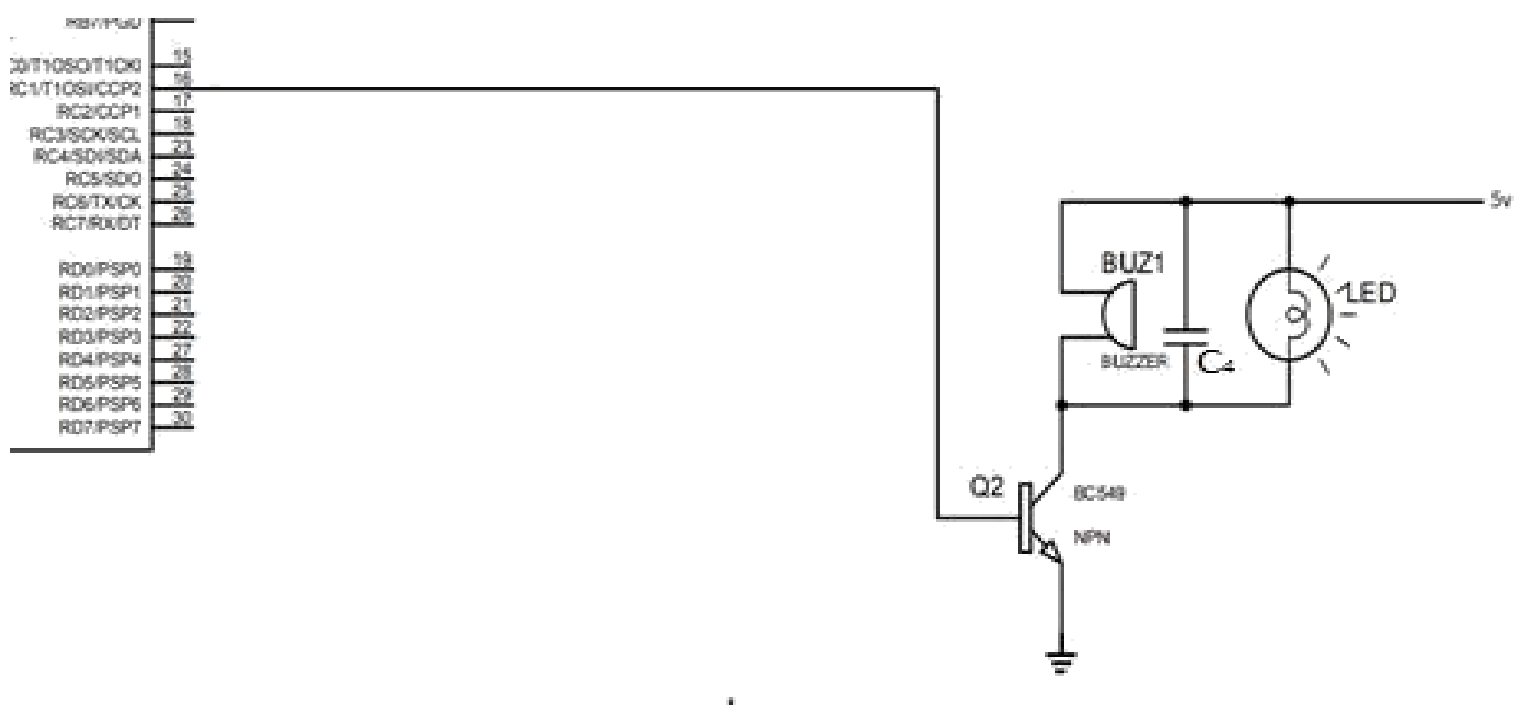

Figure 5: Buzzer connection

The capacitor $\mathrm{C} 4$ serves as a voltage holding capacitor, to keep the LED active for a short time even after the voltage supply is turned off. The voltage across the capacitor, which is time dependent, can be found by using Kirchhoff's current law, where the current discharging the capacitor must equal the current through the load (in this case the internal resistance of the LED serves as the load). This results in the linear differential equation

C.dv/dt $+\mathrm{V} / \mathrm{R}=0$

Where, $\mathrm{C}=$ the capacitance of the capacitor.

Solving this equation for $\mathrm{V}$ yields the formula for exponential decay:

$\mathrm{V}(\mathrm{t})=\mathrm{V}_{0} \mathrm{x} \mathrm{e}^{-\mathrm{t} / R C}$

Where $\mathrm{V}_{0}$ is the capacitor voltage at time $\mathrm{t}=0$. The time required for the voltage to fall to is called the $\mathrm{RC}$ time

constant and is given by: $\tau=\mathrm{RC} 4$.

Where $\tau$ is measured in seconds, $\mathrm{R}$ in Ohms and $\mathrm{C}$ in Farads. To achieve a voltage, hold time of $0.4 \mathrm{sec}$, and taking the internal resistance of the LED bulb to be $820 \Omega$ (measured value at room temperature), we can compute the required capacitor as follows:

$\tau=0.4 \mathrm{~s}$

$\mathrm{R}=820 \Omega$

$\mathrm{C}_{4}=\tau / \mathrm{R}$

$\mathrm{C}_{4}=0.4 \mathrm{~s} / 820 \Omega \mathrm{C}_{4}=$

$465.11 \mu \mathrm{F}$

A $465.11 \mu \mathrm{F}$ capacitor not feasible, thus a $470 \mu \mathrm{F}$ electrolytic capacitor is employed in the design. 


\section{CONTROL BUTTONS}

The control buttons S2, S3 and S4 which indicate increment, decrement and OK respectively were connected to pins 20,21 and 22 of the microcontrollers respectively in an active low mode using the conventional $10 \Omega$ pull up resistors.

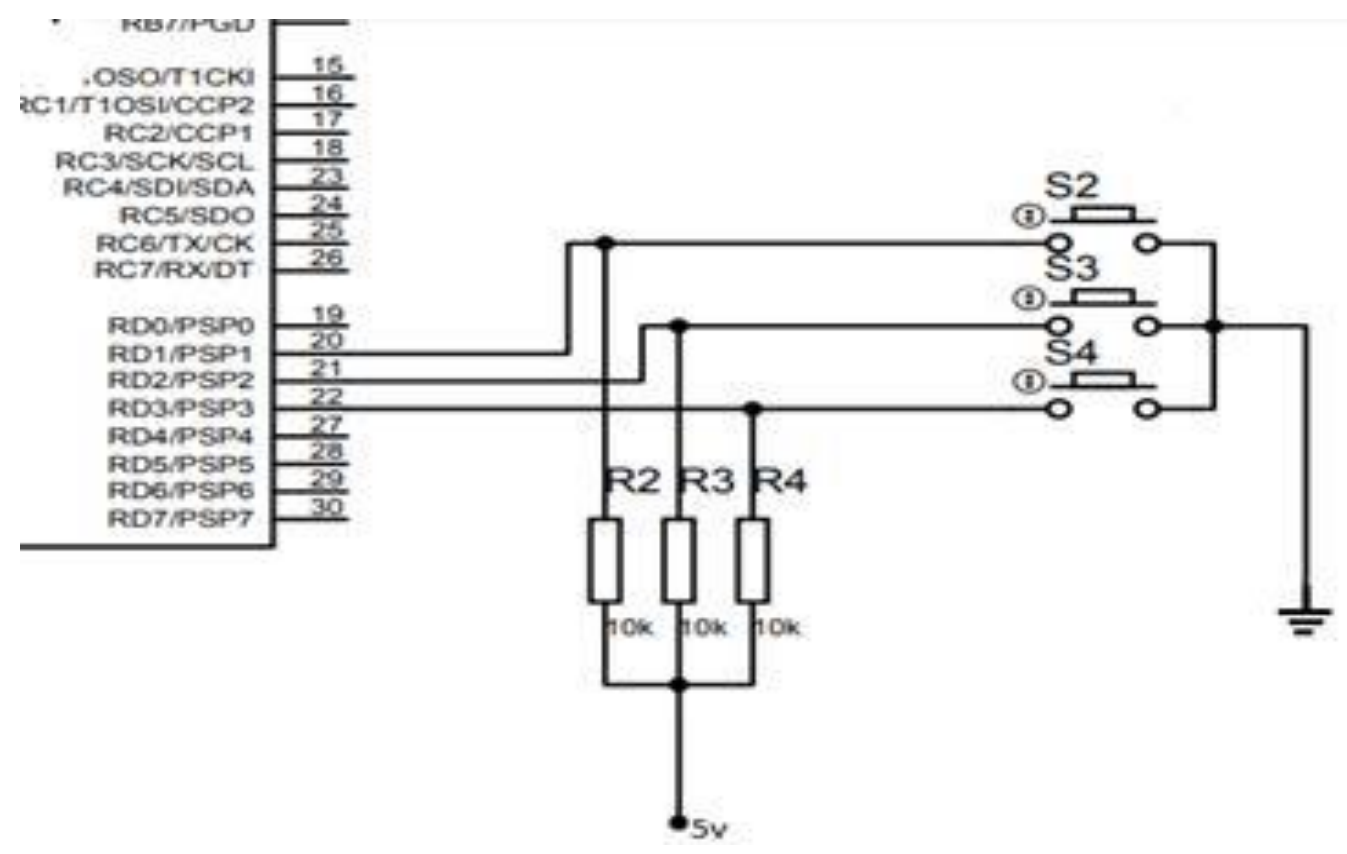

Figure 6: Control buttons

FAN

The fan employed in the design is a $5 \mathrm{~V}$ DC motor with a maximum current rating of $100 \mathrm{~mA}$.

\section{CONSTRUCTION}

Construction of the project consists of various sections which includes gathering and soldering of components on the vero board to form a circuit, loading of program into the microcontroller and casing. Attachment and connection of component with circuit board.

The circuit components are soldered firmly on the vero board which proved mounting surface for them. The vero board is a continuous type which provide room for the use of neater circuit and less use of jumpers. The process of construction is as follows;

Vero board type is chosen - continuous vero board is used in this case. Simulated circuit from Proteus is brought in view as guide.

Each component is mounted and soldered rightly as shown in the working circuit diagram or placed according to choose following the right connection for electric path on the vero board. The circuit is tested for continuity using a multimeter. The continuity test is very important as points where isolation is required may be bridged and this can lead to a total destruction of components as electronic components are very sensitive. Points where continuity are needed are also tested as a break in conduction can lead to malfunction or total failure of the circuit. 


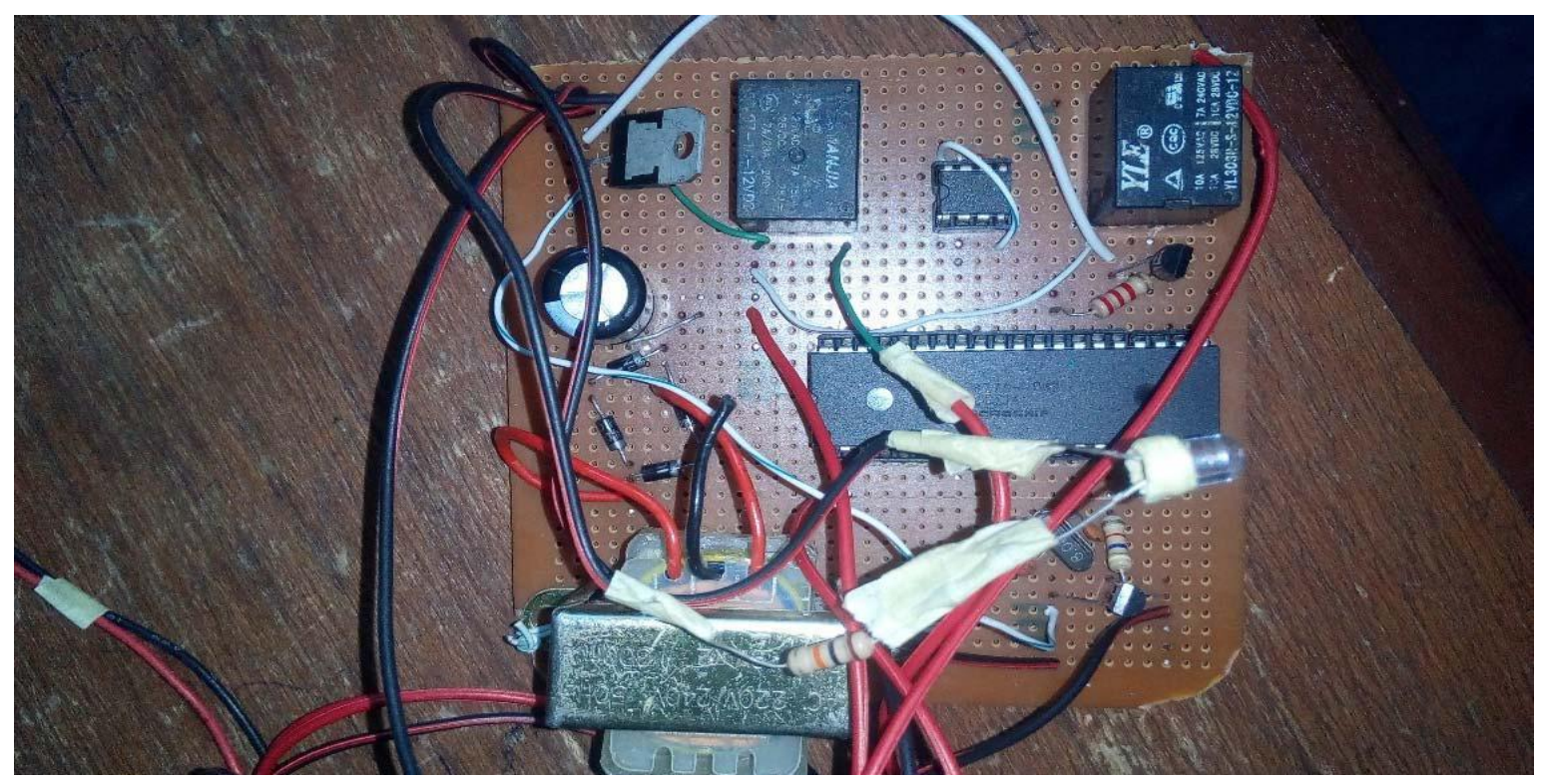

Figure 7: Mounting, circuit coupling and soldering of components

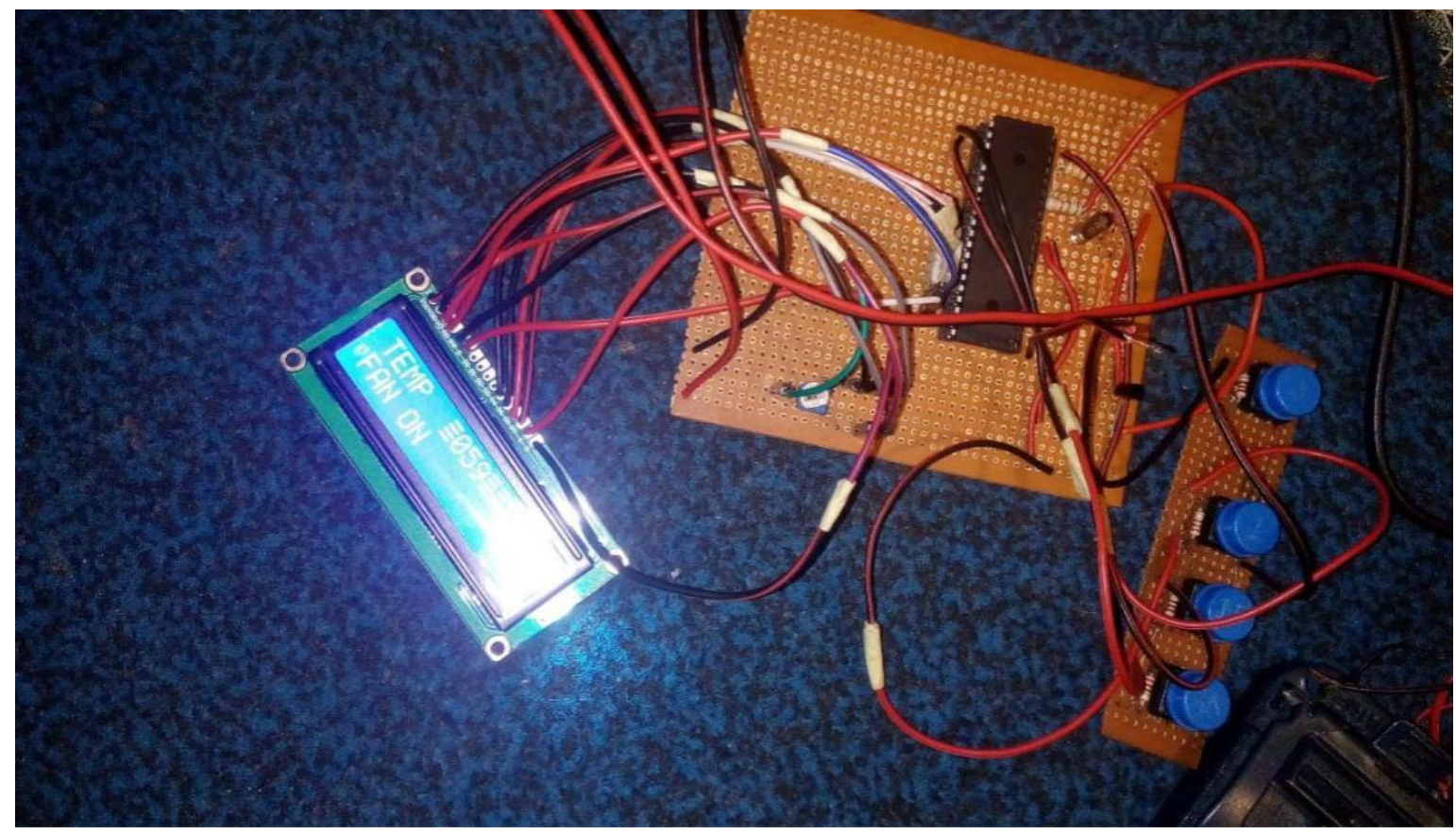

Figure 8: Mounting, Circuit coupling and Soldering of Components 


\section{RESULTS}

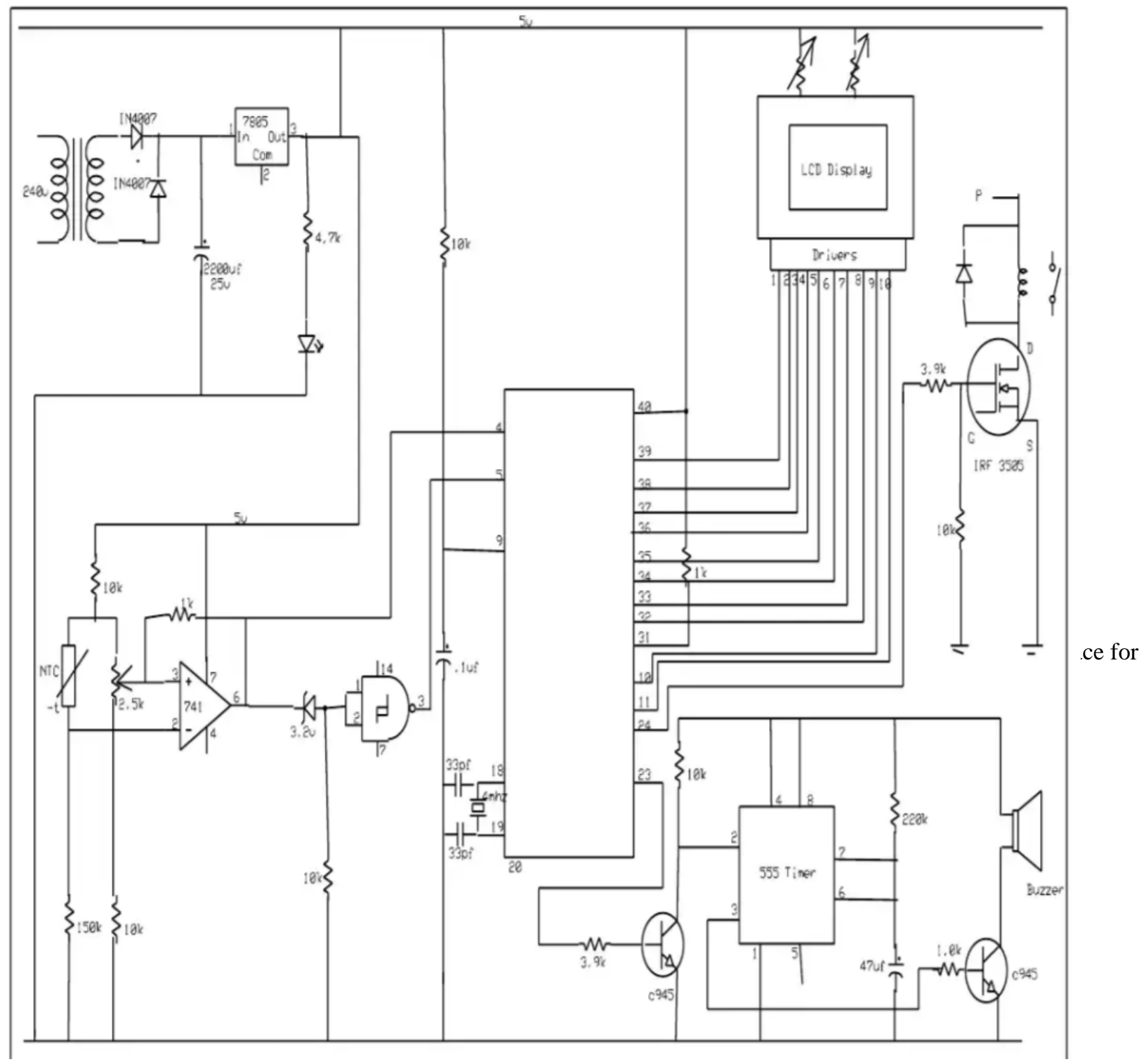

Figure 9: Overall circuit diagram

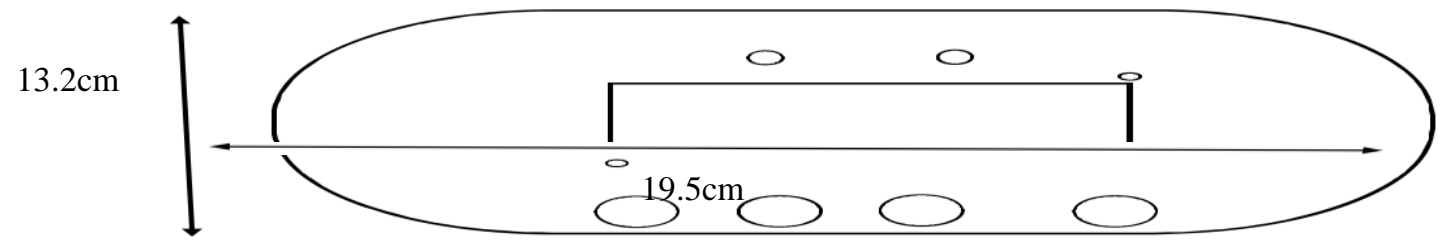

Figure 10: Casing layout and dimension (front view) 


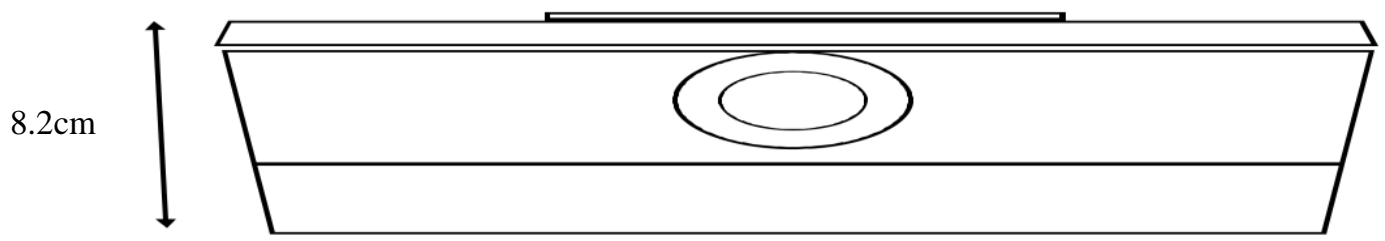

Figure 11: Casing layout and dimension (side view)

\section{PICTORIAL VIEWS FROM THE DESIGN}

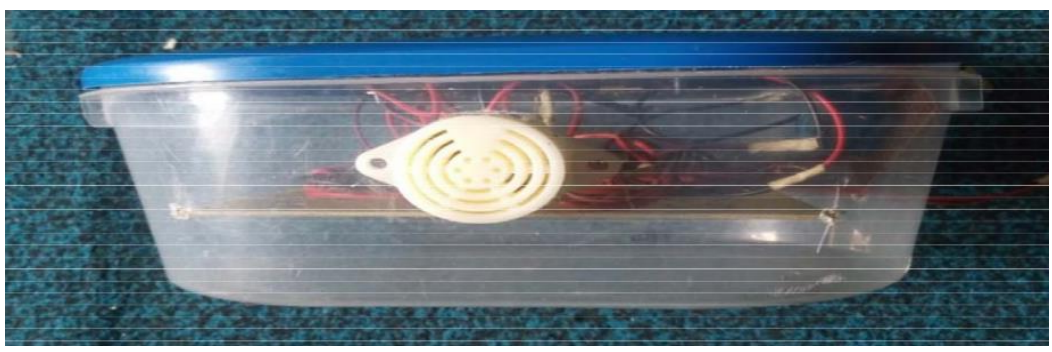

Figure 12: Casing (Side view)

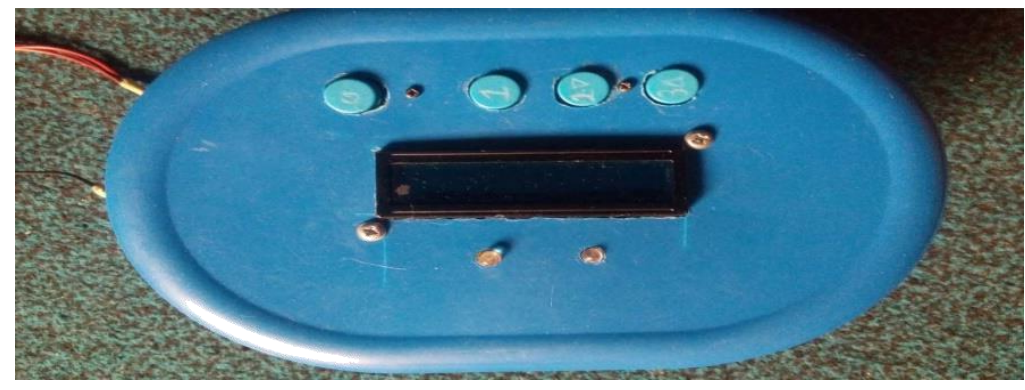

Figure 13: Casing (Top view) 


\begin{tabular}{|c|c|c|c|c|c|}
\hline \multirow{2}{*}{ PARAMETER } & \multirow{2}{*}{ TEST CONDITIONS } & \multirow{2}{*}{$T_{\mathrm{J}} \mathrm{t}^{+}$} & \multicolumn{2}{|r|}{$\mu \mathrm{A} 7805 \mathrm{C}$} & \multirow{2}{*}{ UNIT } \\
\hline & & & M & TYP MAX & \\
\hline \multirow{2}{*}{ Output voltage } & \multirow{2}{*}{$\begin{array}{l}\text { lo }=5 \mathrm{~mA} \text { to } 1 \mathrm{~A}, \quad \mathrm{~V}_{\mathrm{l}}=7 \mathrm{~V} \text { to } 20 \mathrm{~V}, \\
P_{D}=15 \mathrm{~W}\end{array}$} & $25^{\circ} \mathrm{C}$ & & 5.2 & \multirow{2}{*}{$v$} \\
\hline & & $0^{\circ} \mathrm{C}$ to $125^{\circ} \mathrm{C}$ & 4. & 5.25 & \\
\hline \multirow{2}{*}{ Input voltage reguation } & $V_{1}=7 \mathrm{Vto} 25 \mathrm{~V}$ & \multirow{2}{*}{$25^{\circ} \mathrm{C}$} & & 100 & \multirow{2}{*}{$m v$} \\
\hline & $V_{1}=8 \mathrm{~V}$ to $12 \mathrm{~V}$ & & & 50 & \\
\hline Fipple ręection & $V_{1}=8 \mathrm{~V}$ to $18 \mathrm{~V}$ & $0^{\circ} \mathrm{C}$ to $125^{\circ} \mathrm{C}$ & & 78 & $d B$ \\
\hline \multirow{2}{*}{ Output vitage reguation } & $10=5 \mathrm{~mA}$ to $1.5 \mathrm{~A}$ & \multirow{2}{*}{$25{ }^{\circ} \mathrm{C}$} & & 15 & \multirow{2}{*}{$\mathrm{mv}$} \\
\hline & $10=250 \mathrm{~mA}$ to $750 \mathrm{~mA}$ & & & 50 & \\
\hline Output reslistance & $f=1 \mathrm{kHz}$ & $0^{\circ} \mathrm{C}$ to $125^{\circ} \mathrm{C}$ & & 0.017 & $\Omega$ \\
\hline Temperature coeflicent of output votage & $10=5 \mathrm{~mA}$ & $0^{2} \mathrm{C}$ to $125^{\circ} \mathrm{C}$ & & -1.1 & $m V P C$ \\
\hline Output nolse voliage & $\mathrm{f}=10 \mathrm{~Hz}$ to $100 \mathrm{KHz}$ & $25^{\circ} \mathrm{C}$ & & 40 & $\mu \mathrm{V}$ \\
\hline Dropout vatage & $10=1 \mathrm{~A}$ & $25^{\circ} \mathrm{C}$ & & 2 & V \\
\hline Blas current & & $25^{\circ} \mathrm{C}$ & & 4.2 & $\mathrm{~mA}$ \\
\hline \multirow{2}{*}{ Blas current change } & $V_{1}=7 \mathrm{~V}$ to $25 \mathrm{~V}$ & \multirow{2}{*}{$0^{\circ} \mathrm{C}$ to $125^{\circ} \mathrm{C}$} & & 1.3 & \multirow{2}{*}{ mA } \\
\hline & $10=5 \mathrm{~mA}$ to $1 \mathrm{~A}$ & & & 0.5 & \\
\hline Short-circult output curnent & & $25^{\circ} \mathrm{C}$ & & 750 & $m A$ \\
\hline Peak outout curent & & $25^{\circ} \mathrm{C}$ & & 2.2 & $\bar{A}$ \\
\hline
\end{tabular}

Figure 14: Testing results

After thorough check for bridge and continuity, polarity test and earthing test, the device is connected to the main power source which is the same value and potential in its designed operating condition. Various test is carried out on the device. Tests on normal operating condition and worse case scenarios are carried out and data taken.

The designed Automatic temperature control device for inductive loads passed the necessary load tests and analysis conducted with it, thus could be employed for the excessive temperature rise regulation in distribution transformers with high efficiency. Below is the achieved circuit diagram of the automatic temperature control device. 


\section{DISCUSSIONS}

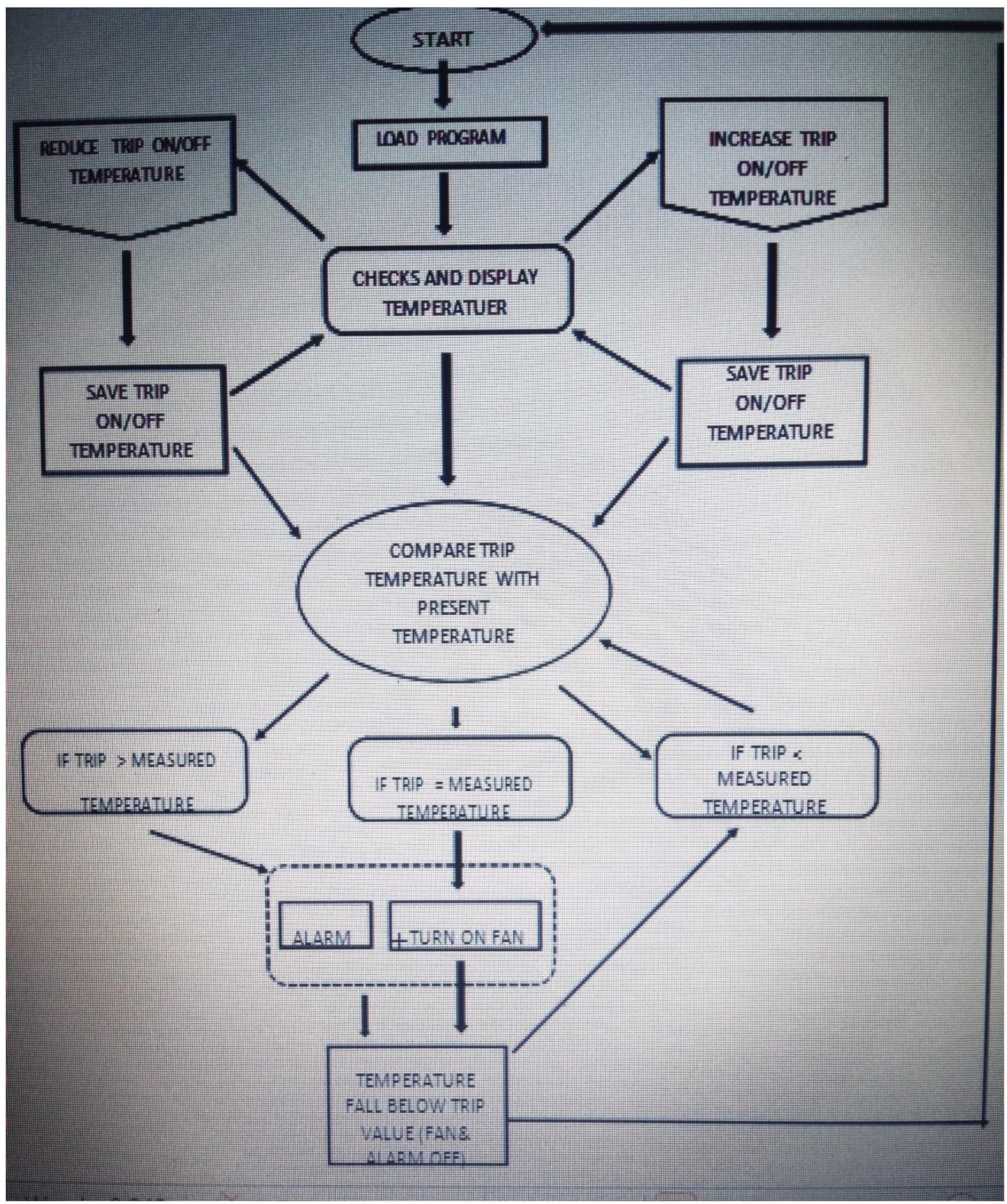

Figure 15: Temperature flow chat of the system 
The LM35 temperature sensor is fixed firmly to the body of the transformer. This temperature sensor produces an analog voltage signal at its output terminal which is directly proportional to the temperature of its environment. The heat dissipated by the transformer is detected by the temperature sensor through conduction and as such the temperature sensor produces an increasing or decreasing voltage signal at its output when the transformer heats up or cools down respectively. This voltage signal is sent through wires to the analog to digital converter (ADC) register of the PIC16877A microcontroller. The ADC converts the analog signals from the temperature sensor to digital signals and stores it in the designated registers of the microcontroller's memory.

Pre-set temperature values are also inputted into designated registers of the microcontroller's memory with aid of three contact switches. These pre-set values are reference values that govern the operation and decisions of the microcontroller. The temperature of the transformer which is required to trigger the fan relay and turn on the fan depicts an example of a pre-set temperature value. If the temperature of transformer exceeds the pre-set value in the microcontroller's memory, the microcontroller triggers the fan relays, thus the fan comes on and blows cool air into the cooling chambers and fins of the transformer. The fan is only turned off when the temperature of the transformer drops below the pre-set value. The LCD screen displays the temperature of the transformer to ensure that the temperature is properly monitored. The LCD also acts as a visual interface between the device operator and the

microcontroller by displaying pre-set temperature values that are being entered and stored in the microcontroller's memory. Lastly the LCD shows changes in the fan status whenever it comes on or goes off.

\section{CONCLUSIONS}

The device is finally tested and proven to work optimally but as always there always is room for modification. Such recommendation and modification would be stated and explained in the section below. This device - automatic temperature control of distribution transformers and can be applied in various aspect of our society where a steady temperature is required such as industries, bakeries, incubators, homes, halls and offices, etc.

- For higher efficiency and longevity, a three-phase induction motor should be used because of their rugged nature and ability to withstand heat and other environmental factors.

- An SMS notification system should also be put in place so as to alert the DSOs whenever temperature values rise above the allowable degree so that he can be notified 


\section{REFERENCE}

Bharathidasan, et al. (2019). Automatic Transformer Cooling System Using PLC. Asian Journal of Sciences, $8(1) 20-24$.

Buyukbicakci et al. (2014). A New Approach for Transformer Cooling System: Application of Phase Change Materials (PCM). Proceedings of the 4th International Congress APMAS2014, April 24-27, 2014, Fethiye, Turkey.

Amuthan et al. (2017). Quadrant Cooling Type Transformer. International Journal of Advanced Research in Electrical, Electronics and Instrumentation Engineering, 6(3)11-13

Bhushan S. Rakhonde, D. and Nikita, A. K. (2014). Microcontroller Based Transformer Cooling Control System. Electrical Department, D.E.S.s C.O.E.T. / S.G.B.A. University, India.

Modi, J. M. (2012). Cooling Control Panel of the Transformer Using Microcontroller and Power Electronics Devices. International Journal of Advancements in Research and Technology, 1(1)12-13

Vladmir, S. and Raj, K. (1998). An Investigation of Power Transformer Cooling with Magnetic Fluids. International Journal of Advanced Research in Electrical, Electronics and Instrumentation Engineering, 5(1)416-422. 


\section{Ni \\ APPENDIX \\ MICROCHIP \\ PIC16F87XA \\ 28/40/44-Pin Enhanced Flash Microcontrollers}

Devices Included in this Data Sheet:

- PIC16F873A

- PIC16F876A

- PIC16F874A

- PIC16F877A

\section{High-Performance RISC CPU:}

- Only 35 single-word instructions to learn

- All single-cycle instructions except for program branches, which are two-cycle

- Operating speed: DC $-20 \mathrm{MHz}$ clock input DC - 200 ns instruction cycle

- Up to $8 \mathrm{~K} \times 14$ words of Flash Program Memory, Up to $368 \times 8$ bytes of Data Memory (RAM), Up to $256 \times 8$ bytes of EEPROM Data Memory

- Pinout compatible to other 28-pin or 40/44-pin PIC16CXXX and PIC16FXXX microcontrollers

\section{Peripheral Features:}

- Timer0: 8-bit timer/counter with 8-bit prescaler

- Timer1: 16-bit timer/counter with prescaler, can be incremented during Sleep via external crystal/clock

- Timer2: 8-bit timer/counter with 8-bit period register, prescaler and postscaler

- Two Capture, Compare, PWM modules

- Capture is 16-bit, max. resolution is 12.5 ns

- Compare is 16-bit, max. resolution is 200 ns

- PWM max. resolution is 10-bit

- Synchronous Serial Port (SSP) with SPITM (Master mode) and I ${ }^{2} \mathrm{C}^{\mathrm{TM}}$ (Master/Slave)

- Universal Synchronous Asynchronous Receiver Transmitter (USART/SCI) with 9-bit address detection

- Parallel Slave Port (PSP) - 8 bits wide with external $\overline{\mathrm{RD}}, \overline{\mathrm{WR}}$ and $\overline{\mathrm{CS}}$ controls (40/44-pin only)

- Brown-out detection circuitry for Brown-out Reset (BOR)
Analog Features:

- 10-bit, up to 8-channel Analog-to-Digital Converter (A/D)

- Brown-out Reset (BOR)

- Analog Comparator module with:

- Two analog comparators

- Programmable on-chip voltage reference (VREF) module

- Programmable input multiplexing from device inputs and internal voltage reference

- Comparator outputs are externally accessible

\section{Special Microcontroller Features:}

- 100,000 erase/write cycle Enhanced Flash program memory typical

- 1,000,000 erase/write cycle Data EEPROM memory typical

- Data EEPROM Retention > 40 years

- Self-reprogrammable under software control

- In-Circuit Serial Programming ${ }^{\mathrm{TM}}$ (ICSP ${ }^{\mathrm{TM}}$ ) via two pins

- Single-supply 5V In-Circuit Serial Programming

- Watchdog Timer (WDT) with its own on-chip RC oscillator for reliable operation

- Programmable code protection

- Power saving Sleep mode

- Selectable oscillator options

- In-Circuit Debug (ICD) via two pins

CMOS Technology:

- Low-power, high-speed Flash/EEPROM technology

- Fully static design

- Wide operating voltage range (2.0V to $5.5 \mathrm{~V}$ )

- Commercial and Industrial temperature ranges

- Low-power consumption

\begin{tabular}{|c|c|c|c|c|c|c|c|c|c|c|c|c|}
\hline \multirow[b]{2}{*}{ Device } & \multicolumn{2}{|c|}{ Program Memory } & \multirow{2}{*}{$\begin{array}{c}\text { Data } \\
\text { SRAM } \\
\text { (Bytes) }\end{array}$} & \multirow{2}{*}{$\begin{array}{c}\text { EEPROM } \\
\text { (Bytes) }\end{array}$} & \multirow[b]{2}{*}{$1 / 0$} & \multirow{2}{*}{$\begin{array}{c}\text { 10-bit } \\
\text { A/D (ch) }\end{array}$} & \multirow{2}{*}{$\begin{array}{l}\text { CCP } \\
\text { (PWM) }\end{array}$} & \multicolumn{2}{|c|}{ MSSP } & \multirow[b]{2}{*}{ USART } & \multirow{2}{*}{$\begin{array}{l}\text { Timers } \\
\text { 8/16-bit }\end{array}$} & \multirow[b]{2}{*}{ Comparators } \\
\hline & Bytes & $\begin{array}{c}\text { \# Single Word } \\
\text { Instructions }\end{array}$ & & & & & & SPI & $\begin{array}{c}\text { Master } \\
\mathrm{I}^{2} \mathrm{C}\end{array}$ & & & \\
\hline PIC16F873A & $7.2 \mathrm{~K}$ & 4096 & 192 & 128 & 22 & 5 & 2 & Yes & Yes & Yes & $2 / 1$ & 2 \\
\hline PIC16F874A & $7.2 \mathrm{~K}$ & 4096 & 192 & 128 & 33 & 8 & 2 & Yes & Yes & Yes & 2/1 & 2 \\
\hline PIC16F876A & $14.3 \mathrm{~K}$ & 8192 & 368 & 256 & 22 & 5 & 2 & Yes & Yes & Yes & $2 / 1$ & 2 \\
\hline PIC16F877A & $14.3 \mathrm{~K}$ & 8192 & 368 & 256 & 33 & 8 & 2 & Yes & Yes & Yes & 2/1 & 2 \\
\hline
\end{tabular}

PIC16F877A PIN DIAGRAM (40 Pins) 


$\begin{aligned} \text { MCLR/VPP } & \longrightarrow \text { (1) } \\ \text { RAO/ANO } & \\ \text { RA1/AN1 } & \end{aligned}$

TABLE 1-1: PIC16F87XA DEVICE FEATURES

\begin{tabular}{|c|c|c|c|c|}
\hline Key Features & PIC16F873A & PIC16F874A & PIC16F876A & PIC16F877A \\
\hline Operating Frequency & $\mathrm{DC}-20 \mathrm{MHz}$ & $\mathrm{DC}-20 \mathrm{MHz}$ & $\mathrm{DC}-20 \mathrm{MHz}$ & $\mathrm{DC}-20 \mathrm{MHz}$ \\
\hline Resets (and Delays) & $\begin{array}{l}\text { POR, BOR } \\
\text { (PWRT, OST) }\end{array}$ & $\begin{array}{c}\text { POR, BOR } \\
\text { (PWRT, OST) }\end{array}$ & $\begin{array}{c}\text { POR, BOR } \\
\text { (PWRT, OST) }\end{array}$ & $\begin{array}{c}\text { POR, BOR } \\
\text { (PWRT, OST) }\end{array}$ \\
\hline $\begin{array}{l}\text { Flash Program Memory } \\
\text { (14-bit words) }\end{array}$ & $4 \mathrm{~K}$ & $4 \mathrm{~K}$ & $8 \mathrm{~K}$ & $8 \mathrm{~K}$ \\
\hline Data Memory (bytes) & 192 & 192 & 368 & 368 \\
\hline EEPROM Data Memory (bytes) & 128 & 128 & 256 & 256 \\
\hline Interrupts & 14 & 15 & 14 & 15 \\
\hline I/O Ports & Ports A, B, C & Ports A, B, C, D, E & Ports A, B, C & Ports A, B, C, D, E \\
\hline Timers & 3 & 3 & 3 & 3 \\
\hline Capture/Compare/PWM modules & 2 & 2 & 2 & 2 \\
\hline Serial Communications & MSSP, USART & MSSP, USART & MSSP, USART & MSSP, USART \\
\hline Parallel Communications & - & PSP & - & PSP \\
\hline 10-bit Analog-to-Digital Module & 5 input channels & 8 input channels & 5 input channels & 8 input channels \\
\hline Analog Comparators & 2 & 2 & 2 & 2 \\
\hline Instruction Set & 35 Instructions & 35 Instructions & 35 Instructions & 35 Instructions \\
\hline Packages & $\begin{array}{l}\text { 28-pin PDIP } \\
\text { 28-pin SOIC } \\
\text { 28-pin SSOP } \\
\text { 28-pin QFN }\end{array}$ & $\begin{array}{c}\text { 40-pin PDIP } \\
\text { 44-pin PLCC } \\
\text { 44-pin TQFP } \\
\text { 44-pin QFN }\end{array}$ & $\begin{array}{l}\text { 28-pin PDIP } \\
\text { 28-pin SOIC } \\
\text { 28-pin SSOP } \\
\text { 28-pin QFN }\end{array}$ & $\begin{array}{c}\text { 40-pin PDIP } \\
\text { 44-pin PLCC } \\
\text { 44-pin TQFP } \\
\text { 44-pin QFN }\end{array}$ \\
\hline
\end{tabular}

\section{N4007 DIODES}

